\title{
Events as an Effective Marketing Communication Tool
}

\author{
Martin Vítek ${ }^{1, *}$ \\ ${ }^{1}$ Institute of Technology and Business, Faculty of Corporate Strategy, Department of Tourism and Marketing, Nemanická 436/7, České \\ Budějovice, Czech Republic
}

\begin{abstract}
A brewery wanted to know how a new beer they were launching would be received by consumers. It was therefore decided to organize an event during which the author of this contribution conducted research. The aim of the research was to find out whether the new product, a low alcohol beer, will attract consumers with its taste, whether its price was set correctly, and whether the targeting and marketing communication tools used were appropriate. The results of the research confirmed that the taste of the new product as well as its price corresponded to the imagination of consumers and that the communication mix was appropriate, but required adjustment to make it even more precise.
\end{abstract}

Keywords: event; event marketing; marketing communication; new product; communication mix

\section{Introduction and literature review}

The marketing communication mix of companies includes in varying degrees, according to the specifics of a particular organization, advertising, direct marketing, sales support, public relations, event marketing and sponsorship, personal sales and online communication. However, as the pace of life accelerates, so the forms and content of individual communication channels need to be adapted. At the same time, it is necessary to keep in mind that the target group is always exposed to the marketing message in a certain communication context, which may strengthen or weaken it [1].

Event marketing is a very specific communication tool. It is based on the direct emotional involvement of the target group, thereby positively affecting the relationship to a particular product or brand. What is important are "experience worlds" that appeal to one or more senses. This includes the use of certain colours, shapes, melodies and smells during events in order to "enhance" the product and give it tactile benefits. This is an active workload in which the target group meets at a specific place and at the same time and perceives a multisensory experience [2].

The success of event marketing is based on the experience of its participants on the basis of secondary - learned motivation. This is formed during a person's development on the basis of conditioned emotional reactions, which is reflected in tendencies to certain appetites [3].

One of the most attractive events are congresses. Participants are enriched through their travel experiences [4]. Congress tourism is a collection of activities, services, economic and social sectors that provide and ensure travel experiences. Since the1950s, the tourism sector has become a rapidly developing and expanding sector of the world economy. In addition to its foreign exchange-earnings effect, tourism is an alternative source of growth for national economies, contributing significantly to national income, employment and the balance of payments [5].

Likewise, exhibitions and trade fairs are also of interest. These are characterized by the confrontation of supply and demand in a specific field of human activity, their periodic nature, their predetermined goal, and rich accompanying programme.

For example, some cities with an interesting history provide grounds for various events to celebrate their founding and therefore become one large exhibition with many exhibits. Hosting special events can be a unique opportunity for boosting tourism development, resulting in loyalty and attachment towards the destination and its assets [6].

Within this context, the event image is transferred to city image. This city image plays a pivotal role in mediating the effect of the event image, on participants satisfaction, and their intention to revisit the host city [7].

The organization of various festivals also falls under event marketing. The word festival usually refers to an organized set of special social events, such as music or film performances. Festival began to be used as a noun in the 16 th century, when it acquired the meaning of a feast or celebration. The term festival as we know it today means a regular recurring programme consisting of cultural performances, exhibitions and competitions. The Latin word festívus, means cheerful,

\footnotetext{
* Corresponding author: vitek@mail.vstecb.cz
} 
joyful, holiday day. The English word festive is derived from the word festívus and means festive, holiday. The use of festivals as promoters of tourist destinations is huge [8].

There are many types of festivals in the world, with most countries celebrating important events or traditions with traditional cultural events and activities. Most festivals offer a variety of speciality foods and drinks to enhance the cultural experience. Satisfaction with the festival experience also significantly influences visitors' attachment to a place and their intentions to recommend a destination [9].

Worldwide, the number and variety of cultural festivals have grown dramatically. Many areas see festivals as an important way to attract tourists, and their spending, to a region, resulting in a positive economic impact [10].

Film, theatre and music festivals can be included among the very popular types of festivals. Each type of festival has its specifics. Hosting film festivals has become a prevailing practice to promote culture or festival tourism [11].

Music festivals can be self-serving, for example, to promote a specific music genre, but it is also very often used as a comprehensive tool for marketing communication. They are used by corporate entities to promote a product or brand, but also used, for example, by cities for their celebrations. In such cases, it is usually multi-genre, intended for a larger number of visitors and therefore includes a larger number of target groups. In the field of marketing, the informational function of music festivals cannot be overlooked [12]. Participants of music festivals who experience changes in their selfconstruct related to self-growth and self-development from their participation in a music festival, use music to facilitate self-awareness and social relatedness [13]. For the organizing entity, however, the most important thing is always the intensive communication with each visitor, not only through music, but a comprehensive experience that can address all senses.

Rock festivals occupy an important place in contemporary consumer culture [14]. In Germany, on the other hand, music and folklore play an important role. A typical example is Oktoberfest, which is one of the most famous beer festivals in the world [8]. The deliberate combination of consuming good beer and a pleasant musical experience deepens the positive experience and perception of a particular brand of drink. Such events offer lovers of craft beer a comfortable but regulated social and physical environment for personal and collective experiences [15].

The town of České Budějovice is home to the brewery Budvar, which many years ago decided that, in addition to its premium brand, it would produce beers that were simpler, low in alcohol and more affordable. On the occasion of the launch of a new beer, the brewery, in cooperation with the author of this contribution, decided to implement an advertising campaign, at the end of which a music festival was organized. This type of event is seen as an important communication tool for strengthening and enriching the mutual business relationships with suppliers and customers [16].

\section{Methodology}

The joint intention of the beer producer and their marketing agency was to organize an event that would support a new product launch. The event took place in summer 2019, during which the author of this contribution and their team carried out research.

It should be noted that the brewery had already done its own research before launching the new beer, to which the author of this contribution did not have access. The research presented here is therefore truly independent, with no team member knowing even basic information about who the target group for the new product was. The only thing the researchers knew was that the taste of the beer had been gradually tuned according to the tastes of specially selected beer consumers, whose sensory properties and evaluation abilities had previously been very carefully verified.

The aim of the research was to find out whether the new product would attract festival visitors with its sensory properties, whether its price was pitched correctly, and whether the selected marketing communication channels were appropriate and effective.

Three research questions were formulated:

\section{What was the composition of the visitors of the music festival?}

2. How did the visitors perceive the different variables of the communication mix which were used by the brewery to promote the event and launch the new beer?

\section{What qualities and characteristics does the beer have in terms of taste and is it reasonably priced?}

The brewery set aside suitable premises at the festival venue and organized the cooperation of other services. The author of this contribution and their team collected the data and then processed it. After mutual assessment, the brewery approved the use of personal questioning as the research method. A structured questionnaire was drawn up consisting of 20 questions split into two parts, each part to be filled in at a different time.

The first part of the questionnaire was filled in when entering the venue and the second upon leaving. The questionnaire contained open questions, closed-ended questions with the option "other", and closed questions for qualitative and quantitative data. The lower age limit of the respondents was set at 18 years, no upper limit was applied. 
At all access points, the agency placed stands with various attractions and simple competitions, which were used to attract people to participate in the personal questioning. Participants were motivated to participate by giving them a voucher for two free beers. When handing over the vouchers, the assistants asked if anyone would be interested in participating in the questionnaire survey and if so, the assistants began to act as interviewers and recorded the respondents' answers on the record sheet. All participants could also win interesting prizes. These were nice gift items with the brewery's logo.

The selection of respondents was not random. They were chosen from those who showed active participation in the competitions, under the assumption that after the music part of the festival they would be willing to complete the questionnaire. Each active participant was assigned an identification number that corresponded to the questionnaire number. After the end of the music, all the numbers were drawn, and the winners were asked final questions during the awards ceremony. A total of 214 respondents aged 18 to 57 participated in the research.

\section{Results and Discussion}

\subsection{Characteristics of respondents}

What was the composition of the festival visitors? The respondents consisted of 117 men and 97 women. Although a balanced number was not achieved, this difference is not important for the targeting of this research.

In order to improve the communication mix for the future, the socio-economic part of the questionnaire sought to establish where the visitors came from.

According to the postcode, a table was compiled showing the number of visitors according to the number of inhabitants of the municipalities and cities from which they came from (Table 1).

Table 1. Respondents by size of town/village they came from

\begin{tabular}{|l|c|c|}
\hline \multirow{2}{*}{ Number of residents } & \multicolumn{2}{|c|}{ Respondents/visitors } \\
\cline { 2 - 3 } & $\mathbf{n}$ & $\%$ \\
\hline more than 80,000 residents & 160 & 74.8 \\
\hline $10,000-79,999$ residents & 17 & 7.9 \\
\hline $4,000-9,999$ residents & 16 & 7.5 \\
\hline smaller villages & 21 & 9.8 \\
\hline Total & $\mathbf{2 1 4}$ & $\mathbf{1 0 0 . 0}$ \\
\hline
\end{tabular}

Source: Author.

Additional data on the selected group of visitors enables the brewery's marketers to compare the results with their target group(s). In accordance with the requirements of the brewery, the level of education and job classification of the visitors was established. This helps to identify and better define particular target groups (Tables 2 and 3).

Table 2. Educational attainment of respondents“

\begin{tabular}{|l|c|c|}
\hline \multirow{2}{*}{ Education } & \multicolumn{2}{|c|}{ Respondents/visitors } \\
\cline { 2 - 3 } & $\mathbf{n}$ & \% \\
\hline University graduate & 57 & 26.6 \\
\hline High school graduate & 148 & 69.2 \\
\hline Elementary school leaver & 9 & 4.2 \\
\hline Total & $\mathbf{2 1 4}$ & $\mathbf{1 0 0 . 0}$ \\
\hline
\end{tabular}

Source: Author.

Table 3. Job classification of respondents

\begin{tabular}{|l|c|c|}
\hline \multirow{2}{*}{ Job classification } & \multicolumn{2}{|c|}{ Respondents/visitors } \\
\cline { 2 - 3 } & $\mathbf{n}$ & $\%$ \\
\hline Manual worker/craftsman & 64 & 29.9 \\
\hline Administration & 118 & 55.1 \\
\hline Manager/businessman & 32 & 15.0 \\
\hline Total & $\mathbf{2 1 4}$ & $\mathbf{1 0 0 . 0}$ \\
\hline
\end{tabular}

Source: Author. 


\subsection{Efficacy of marketing communication mix}

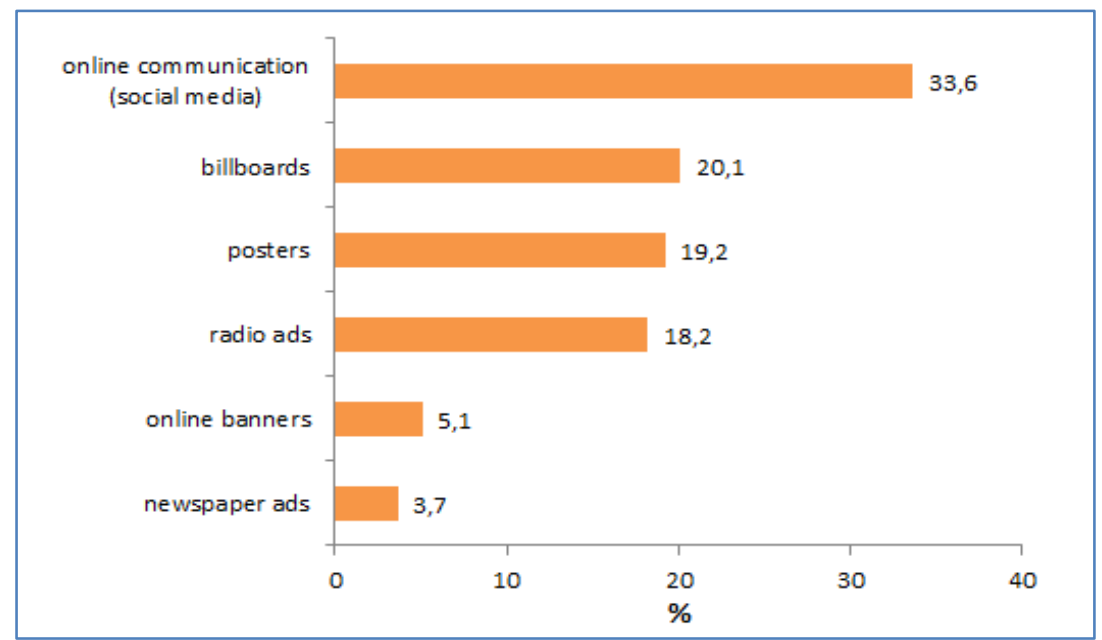

Figure 1. Efficacy of marketing communication mix

Source: Author.

Figure 1 provides the answers to the question, through which marketing communication tools did the respondents learn about the analysed event. In addition to these general findings, the results of the questionnaire survey revealed that for respondents from large cities with a population of more than 10,000 residents, billboards and online advertising were the most attractive, while respondents from cities and municipalities with smaller populations were most attracted by posters and radio advertising. This implies that part of the funds from other marketing communication channels can be redirected towards a billboard campaign in large cities and towards the use of posters in villages. For a better overview, the perceived efficacy of the advertising undertaken from the perspective of respondents is presented in the table below.

The research results show that the respondents were very attracted by radio advertising. Almost everyone agreed that this was due to the funny pre-recorded spots by well-known members of the music groups that performed at the festival. Most of the respondents who said the radio campaign appealed to them, stated that they were travelling to work by car at the time of hearing it. For future radio advertising campaigns, the brewery should increase the frequency of commercials when people are either going to or from work.

\subsection{Evaluation of beer taste}

The preference for beer taste is different in men and women, so the sensory impressions were divided. The evaluation of sensory values showed that the degree of bitterness of the beer was appreciated by $87 \%$ of the respondents. The beer's density was perceived by $20 \%$ of men to be not quite sufficient. However, they agreed that it was a beer with a low alcohol content and therefore fewer substances were released into it at the time of fermentation than stronger beers, for which the fermentation time is significantly longer. The overall taste of the beer was evaluated as medium bitterness, slightly harsh in character, medium-bodied, and with medium-strong sharpness.

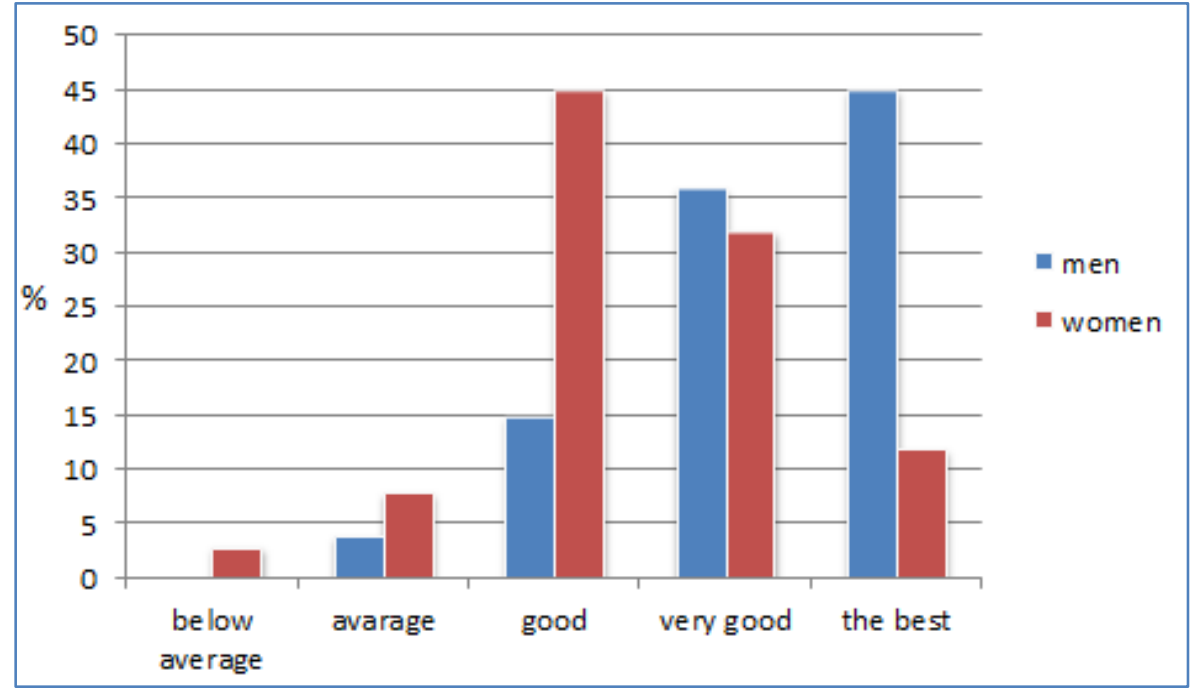

Figure 2. Evaluation of beer taste (in \%)

Source: Author. 
The price of the beer was perceived by most of the women interviewed as reasonable. In contrast, the opinions of the men differed. Men from cities felt that the price could be higher, whereas those from the countryside felt that it corresponded with their ideas or could be lower. In total, however, it was confirmed that the price of the beer set by the brewery corresponded to the expectations of the majority of respondents.

\section{Conclusion}

The main purpose of this contribution was to demonstrate how it is possible to carry out research into a select element of marketing communication - an event, which was organized as part of the presentation of a new product. The goal of the research was fulfilled, not only in its basic part, but also in the related context.

The results of the research will help the brewery verify whether they are communicating properly with their customers. The brewery will also be able to compare their previous findings regarding their target groups. With regards to the taste of the beer, it was established that it was excellent. With regards to price, it was established that this corresponds with consumers' expectations.

In addition to fulfilling the basic goals of the research, it was found that the music festival, as a marketing tool, was appropriate to the target group(s), as was reflected in the positive evaluation of $97 \%$ of the respondents.

\section{References}

1. M. Karlíček, Marketingová komunikace [Marketing comunication]. Praha: Grada Publishing (2016)

2. J. Vysekalová, Emoce v marketingu. [Emotions in marketing]. Praha: Grada Publishing (2014)

3. M. Nakonečný, Motivace chování [Behavior motivation]. Praha: Triton (2014)

4. Ch. Goeldner, R. Brent, Cestovní ruch: principy, př́klady, trendy [Tourism: principles, examples, trends]. Brno: BizBooks (2014)

5. H. O. Saridogan, The Impacts of Tourism Revenues on Economic Growth: Unit Root and Cointegration Tests with Structural Break for Turkey. Eskisehir Osmangazi Universitesi IIBF Dergisi- Eskisehir Osmangazi Universitesi journal of economics and administrative sciences. 15(3), 829-848 (2020)

6. G. Mainolfi, V. Marino, Destination beliefs, event satisfaction and post-visit product receptivity in event marketing. Results from a tourism experience. Journal of business research. 116, 669-710 (2020)

7. H. Li, CH. Lien, SW. Wang, T. Wang, WW. Dong, Event and city image: the effect on revisit intention. Tourism review. In print. (2020)

8. C. B. Kraus, T. F. Fiuza, F. D. Zucco, C. M. B. de Quadros, Satisfaction and engagement of festival visitors: Empirical analysis of an Oktorberfest. Podium-sport leisure and tourism review. 9(2), 308-336 (2020)

9. O. Culha, The effect of food festival quality on place attachment and destination recommendation intention through festival experience and festival satisfaction: The case of the Didim International Olive Festival. Journal of convention \& event tourism. (2020)

10. J. D. Snowball, G. G. Antrobus, Festival value in multicultural contexts: City festivals in South Africa. Tourism economics. (2020)

11. G, Kendall, J. H. T. Chan, M. C. H. Yeung, K.K. Law, Do film festivals attract tourists? Current issues in tourism. (2020)

12. J. D. Montoro-Pons, M. Cuadrado-Garcia, Music festivals as mediators and their influence on consumer awareness. Poetics. 80 (2020)

13. R. Lawendowski, T. Besta, Is participation in music festivals a self-expansion opportunity? Identity, self-perception, and the importance of music's functions. Musicae Scientiae. 24, 206-226 (2020)

14. D. Chaney, Rock festivals as marketplace icons. Consumption markets culture. 23(3), 215-222 (2020)

15. J. Ikaheimo, Exclusive craft beer events: liminoid spaces of performative craft consumption. Food culture \& society. 23(3), 296-314 (2020)

16. H. Lošt’áková, Nástroje na posilování vztahů se zákazníky na B2B trhu. [Tools for strengthening customer relationships in the B2B market]. Praha: Grada Publishing (2017) 